\title{
Gastrointestinal and urinary complaints in adults with hereditary spastic paraparesis
}

\author{
Øivind J. Kanavin ${ }^{1 *}$ and Krister W. Fjermestad ${ }^{2}$
}

\begin{abstract}
Background: Hereditary spastic paraparesis (HSP) is a group of rare genetic disorders affecting the central nervous system. Pure HSP is limited to lower limb spasticity and urinary voiding dysfunction. Complex HSP involves additional neurological features. Beyond the described core symptoms, knowledge about the burden of disease for adults with HSP is limited, particularly regarding gastrointestinal functions, fecal incontinence, and urinary symptoms.

Methods: We conducted a cross-sectional self-report survey with 108 adult HSP patients ( $M_{\text {age }}=57.7$ years, $\mathrm{SD}=11.5$, range 30 to $81 ; 54.2 \%$ females) recruited from a national HSP user group association and a national (non-clinical) advisory unit for rare disorders. HSP data was compared to data from a Norwegian population study, HUNT-3 ( $N=46,293)$.

Results: The HSP group reported more gastrointestinal and urinary complaints compared to controls. Gastrointestinal complaints included at least "much" complaints with constipation (14.6\%) and alternating constipation/diarrhea (8.0\%), and at least daily uncontrollable flatulence (47.6\%), fecal incontinence (11.6\%), and inability to hold back stools (38.5\%). Urinary complaints included frequent urination (27.4\% > 8 times daily), sudden urge (51.9\%) and urinary incontinence (30.5\% at least daily/nightly).

Conclusion: This survey of adults with HSP recruited from non-clinical settings showed constipation, alternate constipation and diarrhea, fecal incontinence, and voiding dysfunction represent considerable problems for many persons with HSP. Health care providers should screen and manage often unrecognized gastrointestinal and fecal incontinence complaints among HSP patients.
\end{abstract}

Keywords: Hereditary spastic paraplegia, Fecal incontinence, Gastrointestinal complaints, Urinary incontinence, Urge incontinence

\section{Background}

The term hereditary spastic paraparesis (HSP) is used to describe a genetically and clinically heterogeneous group of neurodegenerative diseases [1]. Pure forms of HSP affect the lower limbs and lead to slowly progressing spastic weakness, and micturition dysfunction [2]. Complex HSP is not limited to the lower extremities, and may include additional neurological symptoms such as ataxia, extrapyramidal signs, epilepsy, mental retardation, dementia, and peripheral nerve involvement $[1,3]$. Late onset HSP more often leads to rapid progression of symptoms, while early disease debut often heralds slower progression [2]. Several modes of inheritance are

\footnotetext{
* Correspondence: oka@frambu.no

${ }^{1}$ Frambu Centre for Rare Disorders, Sandbakkveien 18, 1404 Siggerud, Norway

Full list of author information is available at the end of the article
}

described, i.e., autosomal recessive, autosomal dominant, and more rarely, X-linked or maternal [4]. Complicated forms of HSP are mostly inherited in an autosomal recessive manner, while pure HSP is commonly inherited in an autosomal dominant manner [4]. At least 79 loci and 60 spastic paraplegia genes are currently identified [5]. In Norway, the site of the current study, the estimated combined prevalence of pure and complex HSP has been reported to be 7.4:100000 [6].

Increased voiding frequency, stress, and urge incontinence linked to neurogenic detrusor over activity has been described in adults with HSP [7-9]. It is less known to what extent fecal incontinence (FI), defined by unintentional loss of solid or liquid stool, is present in the HSP population. This is unfortunate, and in our experience, HSP patients regard FI as an important issue

(C) The Author(s). 2018 Open Access This article is distributed under the terms of the Creative Commons Attribution 4.0 International License (http://creativecommons.org/licenses/by/4.0/), which permits unrestricted use, distribution, and 
to address. The emphasis on FI symptoms was the result of close co-operation with representatives from the HSP patient user group in Norway, who experience reluctance among their members to discuss FI issues with health care providers. Despite lack of optimal treatment solutions for FI, some identified causal factors may be reversed by simple means such as diet, bowel habits, and toilet access [10].

Studies of non-HSP populations have shown FI is rarely disclosed to caregivers due to its' sensitive nature and the stigma attached, and that FI can severely affect quality of life [10-12]. Four studies have examined gastrointestinal complaints in HSP populations. Anal sphincter dysfunction has been reported in HSP [13]. In a Dutch study of 18 HSP patients with a mutation in the SPG11 gene, (SPG11) eight were reported to have developed urinary and fecal incontinence [14]. In a study of 11 adult patients with autosomal dominant pure spastic paraplegia linked to chromosome $2 \mathrm{p}$, five patients had symptoms of FI in addition to urinary incontinence and sexual dysfunction [15]. Recently, in a cohort of 118 HSP patients aged 10 to 84 years recruited from British neurological clinics, $26 \%$ of patients carrying mutations in the SPAST gene associated with SPG4 reported neurogenic bowel symptoms [16].

There have been few studies of the HSP population. Therefore, we conducted a large self-report survey of persons with HSP recruited from non-clinical settings, to examine the prevalence of gastrointestinal and urinary problems in the general HSP population. As symptoms of incontinence increase with age, we included persons aged 30 years and older. Our main research question was: What is the frequency of gastrointestinal complaints, urinary and fecal incontinence among persons with HSP compared to population controls?

\section{Method \\ Sample and procedures HSP sample}

A total of 108 persons with HSP were recruited from two sources. The majority (61\%) was recruited from the register of The National Patients' Association for Hereditary Ataxia and Spastic Paraplegia (NASPA) in Norway. The remaining sample (39\%) was recruited from the database of Frambu Resource Centre for Rare Disorders (Frambu). Frambu is one of nine state-financed centers of expertise administrated by the Norwegian National Advisory Unit on Rare Disorders. Registration in Frambu's patient database is voluntary, based on patient consent, and does not require medical referral. Diagnostic confirmation from a medical institution is required to be registered. Initially we sent out questionnaires to the 60 persons with HSP aged 30 years or older registered in
Frambu's database. The questionnaire was also mailed to 235 NASPA members.

\section{Control sample}

Population data was drawn from the third follow up of the Norwegian epidemiological survey "Helseundersøkelsen i Nord-Trøndelag" (HUNT3) and used as controls [17]. HUNT3 is a comprehensive survey of health. All inhabitants in Nord-Trøndelag County aged 19 years and older were mailed questionnaires and invited to a clinical examination on three different occasions. HUNT3 (2006-2008) comprises the latest population data, providing recent results for gender and age groups comparable to our respondents. The control group comprised 46,293 persons, i.e., all participants aged 30 years and older from HUNT3. The study was planned and performed in cooperation with NASPA and approved by The Regional Committee for Medical and Health Research Ethics (REK South-East).

\section{Measures}

The current survey was part of a larger study covering several areas of functioning [18]. The current report is based on 19 items, all drawn from HUNT3 [17]. Ten items covering urinary symptoms (e.g., frequency of daytime/nighttime urination) were derived from the Epidemiology of Incontinence in the County of NordTrøndelag (EPICONT), and The International Prostate Symptom Score (IPSS) [19]. Six items covering gastrointestinal problems (e.g., frequency of diarrhea, constipation) and three items covering bowel symptoms (e.g, frequency of FI) were developed for the HUNT study [17]. The items covered frequencies, experienced problems, and various details such as amount of leakage and attempted treatments. The questionnaire is available from the first author upon request.

\section{Data analysis}

Data were analyzed using IBM SPSS version 21.0. Comparisons between samples were done by calculating Pearson's chi-square differences for categorical data and Cohen's $d$-effect size differences for scaled data.

\section{Results}

\section{Response rate}

The response rate from patients in the Frambu database was $80 \%$. The exact response rate from the NASPA register is not known, as NASPA also has members with hereditary ataxias. The response rate in HUNT3 was 54\%.

\section{Comparison of samples}

The mean age between the HSP sample and controls was comparable $\left(M_{\mathrm{HSP}}=57.7\right.$ years, $S D=11.5$ vs. $M_{\text {con- }}$ trols $=55.9$ years, $S D=14.0, d=0.13)$. The gender 
distribution between the HSP sample and controls was not significantly different (female ratio ${ }_{\mathrm{HSP}}=53.7 \%$ vs. female ratio $_{\text {controls }}=54.2 \% ; \quad(\chi 2 \quad(1)=0.011, p=.916)$. Within the HSP sample, participants recruited from NASPA were significantly older than participants recruited from Frambu $\left(M_{\mathrm{NASPA}}=59.7\right.$ years, $S D=11.5$ vs. $M_{\text {Frambu }}=54.6$ years, $\left.S D=10.9, d=0.46\right)$. The gender distribution was not significantly different between recruitment settings (female ratio ${ }_{\text {NASPA }}=50.8 \%$ vs. female ratio $_{\text {Frambu }}=59.5 \% ;(\chi 2(1)=0.788, p=.354)$.

\section{Gastrointestinal complaints}

Compared to controls, HSP more often experienced constipation and alternating constipation and diarrhea. Within the HSP sample women reported more nausea, bloating and alternating constipation and diarrhea than men. There was no difference in reported frequency of symptoms between patients with pure and complex HSP. See Table 1.

\section{Fecal incontinence}

Compared to controls, HSP more frequently reported problems with uncontrollable flatulence and stool leakage weekly or daily during the last month. Compared to controls, HSP were less frequently able to hold back stools for $15 \mathrm{~min}$ after first feeling urge to evacuate. Fecal incontinence affected daily life at least weekly in $30 \%$ of the HSP group as well as controls. Within the HSP sample, women reported less ability to hold back their stools. Pure HSP reported more uncontrollable flatulence compared to complex HSP. See Table 2.

\section{Urinary symptoms}

In the HSP sample, both frequent daytime urination and nocturia were reported more often than among controls. HSP confirmed more frequent urinary urgency and involuntary leakage compared to controls. More persons in the HSP sample reported leaking a large amount, and that frequently having to get up at night to urinate was a problem, compared to controls. Within the HSP sample,

Table 1 Percentage of 108 HSP subjects reporting at least "much" gastrointestinal complaints compared to 46,293 controls

\begin{tabular}{lll}
\hline Symptom/severity & Sample & \\
\cline { 2 - 3 } & HSP & Controls \\
\hline Heartburn/acid regurgitation & $5.9 \%$ & $7.3 \%$ \\
Diarrhea & $2.9 \%$ & $7.3 \%$ \\
Constipation & $14.6 \%^{* *}$ & $5.7 \%$ \\
Alternating obstipation/diarrhea & $8.0 \%^{* *, a}$ & $2.9 \%$ \\
Bloating & $7.0 \%^{\mathrm{a}}$ & $11.5 \%$ \\
\hline
\end{tabular}

Note. ${ }^{* *}$ difference between samples is significant at the $p<.001$-level.

${ }^{a}$ significant within HSP sample gender difference, women higher $(p<.05)$
Table 2 Frequency of fecal problems among 108 HSP subjects compared to 46,293 controls

\begin{tabular}{lll}
\hline Symptom & \multicolumn{2}{l}{ Sample } \\
\cline { 2 - 3 } & HSP & Controls \\
\hline Uncontrollable flatulence & & \\
$\quad$ Weekly & $31.4 \%^{* *}$ & $13.5 \%$ \\
$\quad$ Daily & $16.2 \%^{* *}$ & $5.2 \%$ \\
Stool leakage/faecal incontinence & & \\
$\quad$ Weekly & $8.7 \%^{* *}$ & $2.5 \%$ \\
$\quad$ Daily & $2.9 \%^{* *}$ & $0.5 \%$ \\
Fecal incontinence affects daily life & & \\
$\quad$ Weekly & $17.5 \%$ & $16.9 \%$ \\
$\quad$ Daily & $7 \%$ & $9.1 \%$ \\
$\begin{array}{l}\text { Inability to hold back stool 15 min after first } \\
\text { feeling urge to evacuate bowels** }\end{array}$ & $38.5 \%^{* *, a}$ & $13.9 \%$ \\
\hline
\end{tabular}

Note. ${ }^{* *}$ difference between samples is significant at the $p<.001$-level.

${ }^{a}$ significant within HSP sample gender difference, women higher $(p<.05)$

$53.8 \%$ had consulted a doctor because of a leakage problem, and $56.9 \%$ had received treatment. Most reported medical treatment $(81.8 \%)$, followed by pelvic floor exercises (18.2\%) and surgery (9.1\%). Within the HSP sample, subjects with pure HSP reported more problems getting up at night to urinate and women more frequently reported stress urinary incontinence. A detailed summary of the main findings regarding the HSP sample compared to controls is presented in Table 3.

\section{Discussion}

The present report is a survey of gastronintestinal complaints and fecal and urinary incontinence in a large sample of adults with HSP aged $>30$ years recruited from a non-clinical setting. The study measures were drawn from HUNT3, a large population survey, enabling comparison of the HSP sample to population controls. Compared to controls, subjects with HSP experienced more constipation and alternate constipation/diarrhea. Contributing factors may be increased tone in pelvic floor muscles, use of medications, diet, and spending more time sitting and being immobile. In a previously published health survey of the same HSP sample as the current report, participants reported on average $9.0 \mathrm{~h}$ of sitting daily compared to $5.7 \mathrm{~h}$ among controls. Furthermore, $45 \%$ of the HSP sample reported to use a wheelchair outdoors [18]. Constipation may lead to alternating constipation/diarrhea. Constipation is also a known independent risk factor linked to urinary incontinence [20]. As diarrhea may cause FI, keeping stools solid helps to minimize the risk of FI [21].

In a systematic review in multiple sclerosis the reported prevalence of constipation and FI was 40\% [22]. In a survey of patients with amyotrophic lateral sclerosis, 
Table 3 Frequency of urinary problems among 108 HSP subjects compared to controls

\begin{tabular}{|c|c|c|}
\hline \multirow[t]{2}{*}{ Symptom } & \multicolumn{2}{|l|}{ Sample } \\
\hline & $\mathrm{HSP}$ & Controls \\
\hline \multicolumn{3}{|l|}{ Frequency of daytime urination } \\
\hline $8-11$ times & $20.8 \% * *$ & $9.7 \%$ \\
\hline$>11$ times & $6.6 \% * *$ & $1.0 \%$ \\
\hline \multicolumn{3}{|l|}{ Frequency of nighttime urination } \\
\hline$>4$ times & $5.7 \% * *$ & $0.7 \%$ \\
\hline Frequency of nighttime urination experienced as a personal problem & $14.9 \% * *$ & $2.8 \%$ \\
\hline Sudden, compelling urge to urinate that is difficult to suppress at least several times a week & $51.9 \% * *$ & $14.4 \%$ \\
\hline Involuntary loss of urine & $53.7 \% * *$ & $26.2 \%$ \\
\hline In connection with sudden and strong urge to void & $58.3 \%$ & $53.6 \%$ \\
\hline At least daily/nightly & $30.5 \% * *$ & $12.7 \%$ \\
\hline At least a "large" amount & $14.8 \% * *$ & $3.8 \%$ \\
\hline Experienced as personal problem & $21.7 \% * *$ & $8 \%$ \\
\hline
\end{tabular}

Note. **difference between samples is significant at the $p<.001$-level

urge incontinence and constipation, but not FI, was higher compared to healthy controls [23]. Recently, in a cohort of 56 patients with Friedreich's ataxia, 80\% reported lower urinary tract symptoms and 64\% reported bowel symptoms [24]. While urinary urge symptoms are common in HSP, fecal urge is less described. Almost one-third of the HSP subjects in our study reported being unable to hold back stools 15 min after first feeling the urge to evacuate bowels. In an earlier study, 10 of $11 \mathrm{HSP}$ patients had some degree of rectal urgency and decreased anal sphincter tone [15]. In a three-generation family with dominant inherited pure HSP, six of 15 persons reported mild sphincter disturbance [25]. Rectal urgency is often unpredictable, and causes much distress. About onethird of HSP subjects and controls answered that FI interfered with their daily life on a daily or weekly basis, indicating the severity of the problem in both groups. Persons who experience FI tend not to share their condition with others, including their health care providers $[10,21,26]$. In adult patients with Alzheimer's disease and multiple sclerosis, FI and impaired bowel function has been shown to increase anxiety and reduce quality of life [10].

We identified some gender differences within the HSP sample. More women reported bloating and alternating constipation and diarrhea compared to men. Functional gastrointestinal disorders are generally reported to occur more often among women [27]. Within the HSP sample, women more frequently reported both urge FI and stress urinary incontinence. Stress urinary incontinence in women is known to be an independent risk factor for FI, also in the general population [21].
A large proportion of the HSP subjects in our study reported voiding dysfunction in the form of urinary urgency, daytime frequency and nocturua, in addition to incontinence. This is in accordance with previous studies $[7-9,28]$. In our survey we found no significant difference in micturition function between the pure and the complex forms of HSP, which is in accordance with a previous study [9]. Urinary leakage was perceived more of a problem in the HSP group than among controls, and more than half of the HSP responders sought medical advice for involuntary loss of urine and had received treatment, indicating the severity of the problem. The most prevalent reported treatment was medications (82\%). In an Estonian study of 49 persons with HSP, 35\% used medication (oxybutynine) for incontinence [9].

The current survey has limitations. We rely on selfreported complaints, thus excluding the possibility of cross-referencing and validating data with medical records and physical examination. We do not know the exact response rate in the HSP sample, and it may be that those who experience a larger burden are more likely to respond. It is important to note, however, that the data presented herein are part of a larger survey [18]. Thus, we have no reason to believe that persons with more gastrointestinal and urinary complaints would be particularly motivated to respond. Cognitive deficits are known to exist among persons with HSP and may impact self-report accuracy and symptom description. Finally, we did not have access genetic data. Important differences may exist in the symptom areas reported herein depending on genetic subtypes. However, requiring genetic data may have reduced our sample size considerably, particularly older participants. 


\section{Conclusion}

Gastrointestinal complaints and FI in addition to voiding dysfunction affects a considerable number of adult persons with HSP recruited from a non-clinical setting. Health care professionals should actively enquire about symptoms to assess appropriate management interventions for their patients with HSP.

\section{Abbreviations}

HSP: Hereditary spastic paraparesis; HUNT3: The Nord-Trøndelag health study, third wave; M: Mean; NASPA: The National Patients' Association for Hereditary Ataxia and Spastic Paraplegia; SD: Standard deviation

\section{Acknowledgements}

We express our sincere gratitude to the persons with HSP and controls who participated in this study. We thank the board of the Norwegian Patients' Association for Hereditary Ataxia and Spastic Paraplegia (NASPA) for their input in the study, including piloting the questionnaires, recruiting participants, and discussing the results. We thank The Nord-Trøndelag Health Study (The HUNT Study) for access to the population control data. We thank Eva E. Næss, Grete Hummelvoll, and Lise B. Hoxmark for assistance in study planning and data collection. Finally, we thank Dr. Chantal Tallaksen at Oslo University Hospital for reading the manuscript and discussing the results with us.

\section{Funding}

The study was funded by Frambu resource centre for rare disorders.

\section{Availability of data and materials}

The datasets used and analyzed during the current study are available from the corresponding author upon reasonable request.

\section{Authors' contributions}

Both authors were involved in planning and conducting the study, including analyzing the data, writing and completing the current manuscript. Both authors read and approved the final manuscript.

\section{Ethics approval and the consent to participate}

The study was approved by the Regional Committee for Medical and Health Research Ethics (REK South-East), Norway, and written consent was given by the study participants.

\section{Competing interests}

The authors declare that they have no competing interests.

\section{Publisher's Note}

Springer Nature remains neutral with regard to jurisdictional claims in published maps and institutional affiliations.

\section{Author details}

${ }^{1}$ Frambu Centre for Rare Disorders, Sandbakkveien 18, 1404 Siggerud, Norway. ${ }^{2}$ Frambu Department of Psychology, University of Oslo, Oslo, Norway.

Received: 9 October 2017 Accepted: 10 April 2018

Published online: 16 April 2018

\section{References}

1. Salinas S, Proukakis C, Crosby A, Warner TT. Hereditary spastic paraplegia: clinical features and pathogenetic mechanisms. The Lancet Neurology. 2008;7(12):1127-38.

2. Fink JK. Hereditary spastic paraplegia overview. In: Pagon RA, Adam MP, Ardinger HH, Bird TD, Dolan CR, Fong CT, et al., editors. GeneReviews(R). Seattle (WA): University of Washington, Seattle University of Washington, Seattle. All rights reserved.; 1993.

3. Harding AE. Hereditary "pure" spastic paraplegia: a clinical and genetic study of 22 families. J Neurol Neurosurg Psychiatry. 1981;44(10):871-83.

4. Schule R, Schols L. Genetics of hereditary spastic paraplegias. Semin Neurol. 2011;31(5):484-93.
5. Klebe S, Stevanin G, Depienne C. Clinical and genetic heterogeneity in hereditary spastic paraplegias: from SPG1 to SPG72 and still counting. Rev Neurol. 2015;171(6-7):505-30.

6. Erichsen AK, Koht J, Stray-Pedersen A, Abdelnoor M, Tallaksen CM. Prevalence of hereditary ataxia and spastic paraplegia in Southeast Norway: a populationbased study. Brain : a journal of neurology. 2009:132(Pt 6):1577-88.

7. Joussain C, Levy J, Charlanes A, Even A, Falcou L, Chartier-Kastler E, et al. Neurogenic detrusor overactivity in patients with hereditary spastic paraplegias. Ann Phys Rehabil Med. 2016;59S:e104.

8. Fourtassi $M$, Jacquin-Courtois $S$, Scheiber-Nogueira MC, Hajjioui A, Luaute J, Charvier K, et al. Bladder dysfunction in hereditary spastic paraplegia: a clinical and urodynamic evaluation. Spinal Cord. 2012; 50(7):558-62.

9. Braschinsky M, Zopp I, Kals M, Haldre S, Gross-Paju K. Bladder dysfunction in hereditary spastic paraplegia: what to expect? J Neurol Neurosurg Psychiatry. 2010;81(3):263-6.

10. Faecal incontinence in adults: management clinical guideline. United Kingdom: National Institute for health and care excellence; 2007. p. 5.

11. Cotterill N, Norton C, Avery KN, Abrams P, Donovan JL. A patient-centered approach to developing a comprehensive symptom and quality of life assessment of anal incontinence. Dis Colon rectum. 2008;51(1):82-7.

12. Bartlett $L$, Nowak $M, H o Y H$. Impact of fecal incontinence on quality of life. World J Gastroenterol. 2009;15(26):3276-82.

13. Jennum P, Neerup Jensen L, Fenger K, Nielsen JE, Fuglsang-Frederiksen A Nielsen JE. Motor evoked potentials from the external anal sphincter in patients with autosomal dominant pure spastic paraplegia linked to chromosome 2p. J Neurol Neurosurg Psychiatry. 2001;71(4):561-2.

14. De Bot ST, Burggraaff RC, Herkert JC, Schelhaas HJ, Post B, Diekstra A, et al. Rapidly deteriorating course in Dutch hereditary spastic paraplegia type 11 patients. European journal of human genetics : EJHG. 2013; 21(11):1312-5.

15. Jensen LN, Gerstenberg T, Kallestrup EB, Koefoed P, Nordling J, Nielsen JE. Urodynamic evaluation of patients with autosomal dominant pure spastic paraplegia linked to chromosome 2p21-p24. J Neurol Neurosurg Psychiatry. 1998;65(5):693-6.

16. Chelban V, Tucci A, Lynch DS, Polke JM, Santos L, Jonvik H, et al. Truncating mutations in SPAST patients are associated with a high rate of psychiatric comorbidities in hereditary spastic paraplegia. J Neurol Neurosurg Psychiatry. 2017;88(8):681-7.

17. Krokstad S, Langhammer A, Hveem K, Holmen TL, Midthjell K, Stene TR, et al. Cohort profile: the HUNT study, Norway. Int J Epidemiol. 2013;42(4): 968-77.

18. Fjermestad KW, Kanavin OJ, Naess EE, Hoxmark LB, Hummelvoll G. Health survey of adults with hereditary spastic paraparesis compared to population study controls. Orphanet journal of rare diseases. 2016;11(1):98.

19. Hannestad YS, Rortveit G, Sandvik H, Hunskaar S. A community-based epidemiological survey of female urinary incontinence: the Norwegian EPINCONT study. Epidemiology of incontinence in the county of NordTrondelag. J Clin Epidemiol. 2000:53(11):1150-7.

20. Wood LN, Anger JT. Urinary incontinence in women. BMJ (Clinical research ed). 2014;349:g4531.

21. Bharucha AE, Dunivan G, Goode PS, Lukacz ES, Markland AD, Matthews CA, et al. Epidemiology, pathophysiology, and classification of fecal incontinence: state of the science summary for the National Institute of Diabetes and Digestive and Kidney Diseases (NIDDK) workshop. Am J Gastroenterol. 2015;110(1):127-36.

22. Nusrat S, Gulick E, Levinthal D, Bielefeldt K. Anorectal dysfunction in multiple sclerosis: a systematic review. ISRN neurology. 2012;2012: 376023.

23. Nubling GS, Mie E, Bauer RM, Hensler M, Lorenzl S, Hapfelmeier A et al. Increased prevalence of bladder and intestinal dysfunction in amyotrophic lateral sclerosis. Amyotrophic lateral sclerosis \& frontotemporal degeneration. 2014;15(3-4):174-9.

24. Lad M, Parkinson MH, Rai M, Pandolfo M, Bogdanova-Mihaylova P, Walsh RA, et al. Urinary, bowel and sexual symptoms in a cohort of patients with Friedreich's ataxia. Orphanet journal of rare diseases. 2017:12(1):158.

25. Scheltens P, Bruyn RP, Hazenberg GJ. A Dutch family with autosomal dominant pure spastic paraparesis (Strumpell's disease). Acta Neurol Scand. 1990;82(3):169-73.

26. Johanson JF, Lafferty J. Epidemiology of fecal incontinence: the silent affliction. Am J Gastroenterol. 1996;91(1):33-6. 
27. Mayer EA, Naliboff B, Lee O, Munakata J, Chang L. Review article: genderrelated differences in functional gastrointestinal disorders. Aliment Pharmacol Ther. 1999;13(Suppl 2):65-9.

28. Bushman W, Steers WD, Meythaler JM. Voiding dysfunction in patients with spastic paraplegia: urodynamic evaluation and response to continuous intrathecal baclofen. Neurourol Urodyn. 1993;12(2):163-70.

Ready to submit your research? Choose BMC and benefit from:

- fast, convenient online submission

- thorough peer review by experienced researchers in your field

- rapid publication on acceptance

- support for research data, including large and complex data types

- gold Open Access which fosters wider collaboration and increased citations

- maximum visibility for your research: over $100 \mathrm{M}$ website views per year 